\title{
ALTERAÇÕES
}

\section{GASTROINTESTINAIS NO} DIABETES MELLITUS:

\section{estresse oxidativo e fluxo sangüíneo da artéria mesentérica - estudo experimental}

\author{
Alexandre Simões DIAS ${ }^{1,3}$, Susana LLESUY $^{4}$, \\ Cláudio Augusto MARRONI ${ }^{5}$ e Norma MARRONI ${ }^{1,2}$
}

RESUMO - Racional - Os sintomas gastrointestinais são freqüentes no diabetes mellitus e podem estar relacionados com o estresse oxidativo, que é definido pelo desequilíbrio entre os sistemas pró-oxidante e o antioxidante. Objetivo - Avaliar algumas das alterações gastrointestinais no modelo de diabetes mellitus, como o estresse oxidativo no estômago e no fígado de animais diabéticos e o fluxo sangüíneo na artéria mesentérica superior em diferentes tempos de estudo. Material e Métodos - Os parâmetros utilizados para verificar o estresse oxidativo no fígado e no estômago foram a mensuração da lipoperoxidação, através das técnicas das substâncias reativas ao ácido tiobarbitúrico e da quimiluminescência e a avaliação da atividade das enzimas antioxidantes catalase, superóxido dismutase e glutationa transferase. Utilizaramse ratos machos Wistar, pesando entre 250-350 g, que foram divididos em quatro grupos: grupo I - 7 dias de diabetes, grupo II- 30 dias de diabetes, grupo III - 60 dias de diabetes e grupo IV - 90 dias de diabetes. O diabetes foi induzido por administração de estreptozotocina 70 $\mathrm{mg} / \mathrm{kg}$ intraperitonialmente. Resultados - Houve aumento significativo na lipoperoxidação no estômago e no fígado de animais diabéticos somente no tempo de 90 dias. No estômago, foi encontrada significativa diminuição na atividade das enzimas antioxidantes catalase e glutationa transferase. No fígado, somente a enzima glutationa transferase apresentou diminuição significativa. Houve aumento no fluxo da artéria mesentérica superior dos animais diabéticos com 90 dias, quando comparados aos animais-controle. Conclusões - É possível supor que o aumento no estresse oxidativo no estômago e no fígado e a alteração no fluxo sangüíneo da artéria mesentérica superior sejam influenciados pelo tempo de diabetes e pela hiperglicemia encontrada nos animais estudados, o que determinaria as alterações gastrointestinais.

DESCRITORES - Diabetes mellitus experimental. Estresse oxidativo. Fluxo sangüíneo regional. Artérias mesentéricas. Ratos.

\section{INTRODUÇÃO}

O diabetes mellitus (DM) é uma síndrome clínica heterogênea, caracterizada por anormalidades endrócrino-metabólicas, que tem como elementos fundamentais deficiência absoluta ou relativa na fração secretora da insulina pelo pâncreas e/ou deficiência na ação da insulina em tecidos alvo, bem como alteração no metabolismo dos carboidratos, lipídios e proteínas. É caracterizada clinicamente pela poliúria, polidipsia, perda de peso apesar da polifagia, hiperglicemia, glicosúria, cetose, acidose e, em casos mais graves, o coma.
O estresse oxidativo pode ser responsável pelos sintomas apresentados pelos pacientes com DM; é definido quando há alteração no balanço pró-oxidante e antioxidante ${ }^{(1,21)}$. As alterações por ele causadas podem ocorrer na condução nervosa, na autooxidação da glicose sangüínea, na formação de glicosilação avançada e na atividade da enzima aldose redutase ${ }^{(15)}$

Diversas complicações clínicas ocorrem, principalmente, 6 meses após diagnosticada a doença, quando os sintomas gastrointestinais são os mais incidentes. Destaque deve ser dado para a gastropatia diabética, disfunção que ocorre no estômago e que inclui anormalidades na contratilidade gástrica, no tônus muscular e na atividade mioelétrica gástrica ${ }^{(14,24)}$.

\footnotetext{
${ }^{1}$ Laboratório de Fisiologia Digestiva, Universidade Federal do Rio Grande do Sul; ${ }^{2}$ Universidade Luterana do Brasil. ${ }^{3}$ Rede Metodista de Educação - Instituto Porto Alegre, Porto Alegre, RS; ${ }^{4}$ Universidad de Buenos Aires, Argentina. ${ }^{5}$ Fundação Faculdade Federal de Ciências Médicas de Porto Alegre, RS.

Endereço para correspondência: Dr. Cláudio Augusto Marroni - Rua José Kanan Aranha, 102 - Bairro Jardim Isabel - 91760-470 - Porto Alegre, RS. nmarroni@terra.com.br
} 
O fígado executa papel central na manutenção da glicemia, pois está envolvido no metabolismo dos carboidratos, dos lipídios e mais especificamente, na gliconeogênese e na glicogenólise. Devido a essencial participação no controle do metabolismo corporal, esse órgão pode ser afetado no DM e na hiperlipidemia ${ }^{(9)}$.

Pacientes diabéticos apresentam alterações hepáticas, entre as quais destacam-se a esteatose, a esteatohepatite não-alcoólica e a cirrose $^{(9)}$. As complicações vasculares representam a principal causa de morbidade e mortalidade em pacientes diabéticos e ocorrem na micro e na macrovasculatura. A hiperglicemia pode aumentar a geração das espécies ativas de oxigênio através da auto-oxidação da glicose, pela ativação da proteína quinase $\mathrm{C}$ ou pelo aumento do metabolismo na via dos polióis ${ }^{(28)}$. Em estudo experimental realizado por $\mathrm{MELO}^{(19)}$, utilizando estreptozotocina (STZ), ficou demonstrado que 18 horas após a indução do DM ocorreu dano nas células beta pancreáticas, provavelmente causado pelo desequilíbrio nos sistemas pró e antioxidantes.

O presente trabalho avaliou o estresse oxidativo no fígado e no estômago de animais diabéticos e controles em diferentes tempos de indução da doença, bem como o fluxo sangüíneo na artéria mesentérica superior, na tentativa de relacionar os mecanismos fisiológicos existentes.

\section{MATERIAIS E MÉTODOS}

Foram utilizados ratos machos, Wistar, com peso entre 250 e $350 \mathrm{~g}$, provenientes do Biotério do Instituto de Ciências Básicas da Saúde da Universidade Federal do Rio Grande do Sul - UFRGS, Porto Alegre, RS.

Todos os procedimentos realizados estavam de acordo com as normas estabelecidas pela Comissão de Pesquisa e Ética em Saúde contidas na Pesquisa em Saúde e Direito dos Animais, de autoria do grupo de pesquisa e pós-graduação do Hospital de Clínicas de Porto Alegre ${ }^{(10)}$.

Os animais foram divididos em quatro grupos, cada um composto por 7 animais diabéticos e 7 animais-controle: grupo I - 7 dias de diabetes, grupo II- 30 dias, grupo III - 60 dias e grupo IV - 90 dias. Utilizou-se somente um grupo-controle para todos os tempos, pois não houve diferença estatisticamente significativa entre as variáveis avaliadas nos tempos estudados. O DM foi induzido por única injeção intraperitonial de STZ (Sigma Chemical Co., St. Louis, MO, EUA) $70 \mathrm{mg} / \mathrm{kg}^{(25)}$. Os animaiscontrole receberam somente tampão citrato de sódio intraperitonial.

Para determinação da glicemia, utilizou-se o teste enzimático colorimétrico (Kit Enzi-Color, Bio-Diagnóstica), em que um reagente foi misturado a $20 \mu \mathrm{L}$ de amostra do plasma e lido em espectrofotômetro (Cary 3E - UV-Visible Spectrophotometer Varian), com comprimento de onda de $500 \mathrm{~nm}$. Foram considerados diabéticos os animais que apresentaram a concentração de glicose sangüínea acima de $250 \mathrm{mg} / \mathrm{dL}^{(22)}$.

Ao término do período preconizado para cada grupo, foram retirados os estômagos e os fígados dos animais, que foram homogeneizados em Ultra-Turrax (IKA-WERK) durante 1 minuto (estômago) e 40 segundos (fígado), à temperatura de $0 \mathrm{a} 2^{\circ} \mathrm{C}$. Esse homogeneizado foi centrifugado em centrífuga refrigerada (SORVALL RC-5B Refrigerated Superspeed Centrifuge), por 10 minutos a 3.000 rotações por minuto $(1.110 \mathrm{x}$ g). O precipitado foi desprezado e o sobrenadante retirado e congelado em freezer à temperatura de $-70^{\circ} \mathrm{C}$.

Para a verificação do estresse oxidativo no fígado e no estômago, foi utilizada a mensuração da lipoperoxidação através das técnicas das substâncias reativas ao ácido tiobarbitúrico (TBA-RS) e da quimiluminescência (QL) e a avaliação da atividade das enzimas antioxidantes catalase (CAT), superóxido dismutase (SOD) e glutationa transferase (GTx).
A técnica de TBA-RS consiste no aquecimento do homogeneizado com ácido tiobarbitúrico e na conseqüente formação de um produto corado, medido em espectrofotômetro a $535 \mathrm{~nm}$. Essa técnica utiliza o malondealdeído (MDA) para a quantificação das substâncias reativas. A concentração de TBA-RS obtida foi expressa em nmol por mg de proteína ${ }^{(3)}$.

O método para determinar a quimiluminescência consiste em adicionar um hidroperóxido orgânico de origem sintética (hidroperóxido de tertbutila) ao homogeneizado de tecido em estudo. A QL foi medida em um contador com o circuito de coincidência desconectado e utilizado o canal de tritio (Liquid Scintillation Correnter, 1209 RACKBETA, LKB WALLAR) operando como um luminômetro. Os resultados foram expressos em contagem por segundo (cps) por mg de proteína ${ }^{(12)}$.

A atividade da enzima CAT foi avaliada pela determinação, em espectrofotômetro, da velocidade de decomposição do peróxido de hidrogênio $\left(\mathrm{H}_{2} \mathrm{O}_{2} 0,3 \mathrm{M}\right)$ com um comprimento de onda de $240 \mathrm{~nm}$. A atividade enzimática foi expressa em nmol por mg de proteína ${ }^{(2)}$.

A determinação da enzima SOD foi baseada na inibição da reação do radical superóxido com a adrenalina. A SOD, presente na amostra em estudo, competiu pelo radical superóxido através do sistema de detecção. Os resultados foram expressos em unidades de SOD por $\mathrm{mg}$ de proteína.

A atividade da enzima GTx consiste na formação da 2,4 dinitrofenilS-glutationa e foi avaliada em espectrofotômetro (marca Varian, modelo Cary) com comprimento de onda de $340 \mathrm{~nm}$. Os resultados foram expressos em $\mathrm{nmol} / \mathrm{mg}$ de proteína ${ }^{(16)}$.

A avaliação do fluxo sangüíneo foi realizada na artéria mesentérica superior, onde os animais foram anestesiados com cloridrato de Ketamina (Ketalar) e cloridrato 2-(2,6-xilidino)-5,6-dihidro-4H-1,3 tiazina (Rompum ), numa proporção de $180 \mathrm{mg} / \mathrm{kg}$ de Ketalar para 50 $\mathrm{mg} / \mathrm{kg}$ de Rompum . O fluxo na artéria mesentérica superior foi avaliado pelo fluxômetro ultra-sônico (Transonic System Inc. modelo T106) conectado a um conversor analógico-digital, (STEMTECH, INC) e esse, a um computador (PC 486) com o software (CODAS/WINDAQ), permitindo a análise de dados numa freqüência de $1 \mathrm{KHz}$

\section{Análise estatística}

Os resultados foram expressos como média \pm erro padrão da média para cada grupo experimental. Foi utilizado o software GraphPad Instat, versão 3.0 para Windows 95 (GraphPad Software, San Diego, Califórnia, EUA).

$\mathrm{Na}$ avaliação paramétrica e não-paramétrica dos dados foi utilizado o método de Bartlett. A avaliação da normalidade (distribuição gaussiana) dos dados foi realizada com o emprego do método de Kolmogorov e Smirnov. Para os dados não-pareados utilizou-se a análise da variância simples (ANOVA), a fim de comparar as diferenças observadas em cada parâmetro estudado. Foi aplicado também o teste complementar de Tukey-Kramer para comparações múltiplas. O nível de significância utilizado foi de $5 \%(P<0,05)$.

\section{RESULTADOS}

Os resultados estão apresentados em tabelas e gráficos nos diferentes grupos experimentais e nos diferentes tempos de indução do DM.

A partir da análise do peso corporal, utilizou-se somente um grupo-controle (sete animais) para todas as variáveis estudadas pois, no momento do sacrifício, não houve diferença significativa entre os animais nos diferentes tempos de DM. Não houve diferença significativa no peso dos diferentes grupos (T0). 
A Tabela 1 apresenta o peso dos animais no momento do sacrifício. Houve diminuição significativa no peso dos animais diabéticos em todos os momentos estudados $(P<0,001)$.

No Gráfico 1, estão expressos em mg/dL as glicemias dos animais em diferentes tempos de DM. No tempo zero (T0), não houve diferença entre os grupos. Os animais diabéticos aos 7, 30, 60 e 90 dias apresentaram aumento significativo na glicemia, em todos os tempos estudados $(P<0,001)$.

TABELA 1 - Peso dos animais no momento do sacrifício nos diferentes grupos estudados

\begin{tabular}{ccc}
\hline Grupo & Controle $(\mathrm{g})$ & Diabético $(\mathrm{g})$ \\
\hline Tempo 7 & $349 \pm 8,8$ & $280 \pm 12,0^{\mathrm{a}}$ \\
Tempo 30 & $320 \pm 5,5$ & $222 \pm 7,6^{\mathrm{a}}$ \\
Tempo 60 & $350 \pm 21,4$ & $273 \pm 13,9^{\mathrm{a}}$ \\
Tempo 90 & $417 \pm 6,0$ & $223 \pm 12,8^{\mathrm{a}}$ \\
\hline
\end{tabular}

a - diferença significativa entre os grupos diabéticos e o grupo controle $(\mathrm{Pm}<0,001)$

g- gramas

GRÁFICO 1 - Glicemia dos animais diabéticos e controles no dia da indução (T0) e no dia do sacrifício

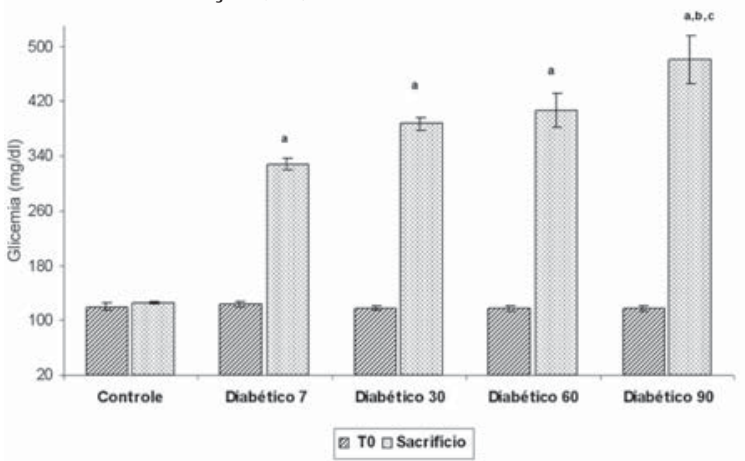

a diferença significativa entre os grupos diabéticos 7, 30, 60 e 90, respectivamente, e o grupo controle no dia do sacrifício $(P<0,001)$

${ }^{\mathrm{b}}$ diferença significativa entre o grupo diabético 90 e o grupo diabético $7(P<0,001)$

c diferença significativa entre o grupo diabético 90 e o grupo diabético $30(P<0,001)$

\section{Lipoperoxidação no estômago}

Na Tabela 2, estão expressos os valores da lipoperoxidação no estômago dos animais do grupo controle e diabéticos nos diferentes tempos de DM. Nota-se que os animais diabéticos aos 90 dias apresentam diferença significativa em relação ao grupo controle tanto na técnica de TBA-RS, quanto na QL $(P<0,01)$ e que o grupo diabético aos 7 dias também mostrou diferença significativa em relação ao grupo diabético de 90 dias na técnica de QL $(P<0,05)$.

TABELA 2 - Resultados da lipoperoxidação obtidos pelas técnicas do TBARS e QL no estômago dos animais controle e diabéticos nos diferentes grupos

\begin{tabular}{lcc}
\hline Grupo & $\begin{array}{c}\text { TBA-RS } \\
\text { (nmol/mg proteína) }\end{array}$ & $\begin{array}{c}\text { QL } \\
\text { (cps/mg proteína) }\end{array}$ \\
\hline Controle & $0,22 \pm 0,02$ & $247,2 \pm 16,0$ \\
Diabético 7 & $0,24 \pm 0,07$ & $243,1 \pm 21,8$ \\
Diabético 30 & $0,33 \pm 0,09$ & $345,8 \pm 25,2$ \\
Diabético 60 & $0,20 \pm 0,03$ & $246,2 \pm 12,2$ \\
Diabético 90 & $0,44 \pm 0,02^{\mathrm{a}}$ & $391,2 \pm 32,6^{\mathrm{a}, \mathrm{b}}$ \\
\hline a - diferença significativa entre o grupo diabético 90 e $\circ$ grupo controle $(P<0,01)$ \\
b- diferença significativa entre o grupo diabético 90 e $\circ$ grupo diabético $7(P<0,05)$
\end{tabular}

Enzimas antioxidantes no estômago

Houve redução na atividade das enzimas antioxidantes no estômago e diferença significativa na atividade da CAT nos animais diabéticos de 7, 60 e 90 dias $(P<0,05)$ e na GTx aos 7 e 90 dias $(P<0,05)$ (Graficos 2, 3).

GRÁFICO 2 - Medida da atividade da enzima catalase (CAT) em homogeneizado de estômago de animais controles e

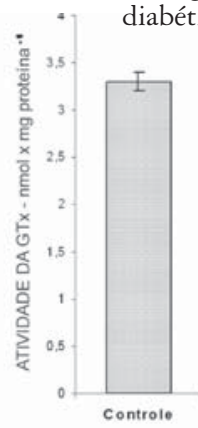
éticos

diferença significativa
controle $(P<0,05)$

GRÁFICO 3 - Medida da atividade da enzima glutationa transferase (GTx) em homogeneizado de estômago de animais controles e diabéticos

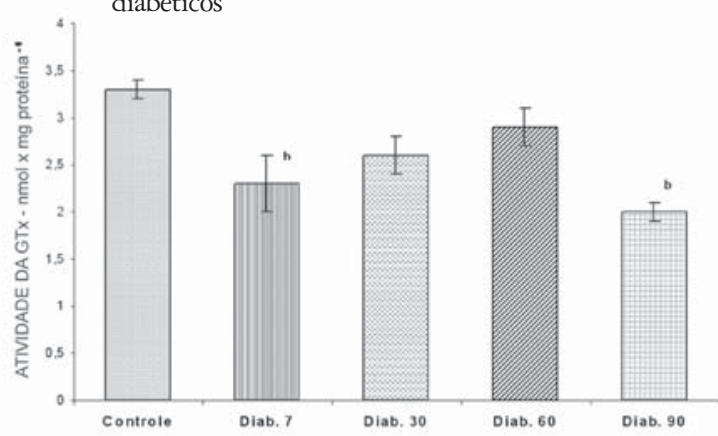

${ }^{b}$ diferença significativa entre os grupos diabéticos 7 e 90 , respectivamente, e o grupo controle $(P<0,05)$

\section{Lipoperoxidação no fígado}

Na Tabela 3, estão expressos os valores da lipoperoxidação no fígado dos animais controles e diabéticos nos diferentes tempos de indução. Notase que a lipoperoxidação dos animais diabéticos aos 90 dias aumentou significativamente, quando comparada ao grupo-controle, tanto na técnica de TBA-RS quanto por QL $(P<0,001)$. Observa-se também que os animais diabéticos aos 90 dias diferem nos outros tempos de indução 7, 30 e 60, para TBA-RS $(P<0,01)$ e para QL $(P<0,001)$.

TABELA 3 - Resultados da lipoperoxidação obtidos pelas técnicas do TBARS e QL em fígado dos animais controle e diabéticos nos diferentes grupos

\begin{tabular}{lcc}
\hline Grupo & $\begin{array}{c}\text { TBA-RS } \\
(\mathrm{nmol} / \mathrm{mg} \text { proteína) }\end{array}$ & $\begin{array}{c}\text { QL } \\
\text { (cps/mg proteína) }\end{array}$ \\
\hline Controle & $1,51 \pm 0,06$ & $1669,1 \pm 58,9$ \\
Diabético 7 & $1,34 \pm 0,02$ & $1892,2 \pm 97,2$ \\
Diabético 30 & $1,46 \pm 0,25$ & $1567,6 \pm 71,2$ \\
Diabético 60 & $1,13 \pm 0,09$ & $1538,6 \pm 135,3$ \\
Diabético 90 & $2,45 \pm 0,21^{\mathrm{a}, \mathrm{b}}$ & $2660,8 \pm 108,1^{\mathrm{a}, \mathrm{b}}$ \\
\hline a - diferença significativa entre o grupo diabético 90 e o grupo controle $(P<0,001)$ \\
$\mathrm{b}$ - diferença significativa entre o grupo diabético 90 e os 7,30 e 60, respectivamente $(P<0,01)$
\end{tabular}




\section{Enzimas antioxidantes no fígado}

Houve redução significativa na atividade da GTx nos animais diabéticos aos 60 e 90 dias $(P<0,05)$ (Gráfico 4$)$. A atividade das demais enzimas antioxidantes (CAT e SOD), estudadas no fígado, não apresentou diferença estatisticamente significativa, mas apresentou tendência à redução.

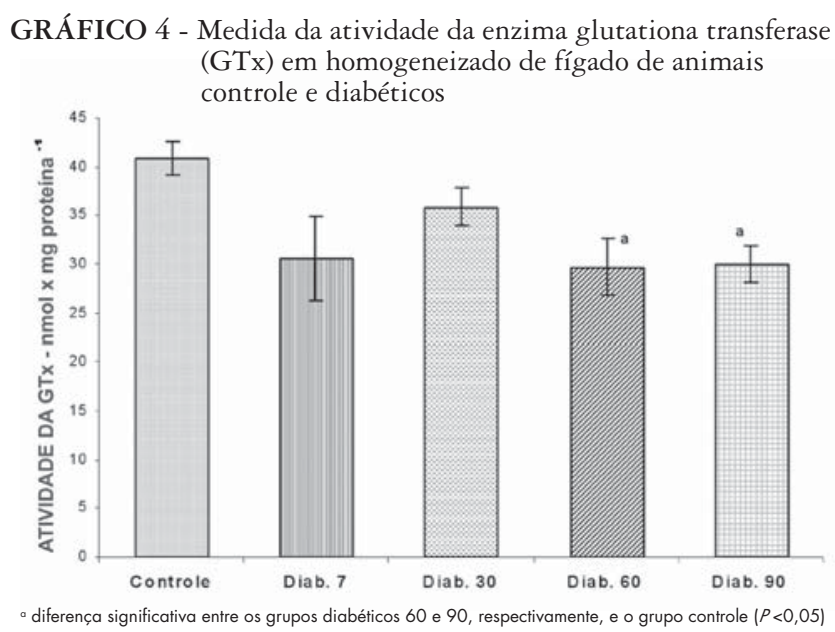

\section{Fluxo sangüíneo na artéria mesentérica superior}

A medida do fluxo sangüíneo foi realizada na artéria mesentérica superior e expressa em $\mathrm{mL} / \mathrm{min}$. Na Tabela 4, observa-se aumento significativo no fluxo sangüíneo no grupo DM aos 90 dias, quando comparado com o grupo controle $(P<0,001)$. Nos demais tempos estudados, não houve diferença.

TABELA 4 - Resultados da mensuração do fluxo sangüíneo na artéria mesentérica superior de animais controle e diabéticos

\begin{tabular}{lc}
\hline Grupo & Fluxo $(\mathrm{mL} / \mathrm{min})$ \\
\hline Controle & $12,03 \pm 0,32$ \\
Diabético 7 & $13,84 \pm 0,61$ \\
Diabético 30 & $12,30 \pm 1,16$ \\
Diabético 60 & $13,77 \pm 0,61$ \\
Diabético 90 & $15,24 \pm 0,31^{\mathrm{a}}$ \\
\hline
\end{tabular}

a - diferença significativa entre o grupo diabético 90 e $\circ$ grupo controle $(P<0,001)$

\section{DISCUSSÃO}

O modelo experimental de DM é muito utilizado e contribui para melhor entendimento da sua fisiopatologia em humanos. Diversos agentes químicos são utilizados para desenvolve-lo em animais, dentre os quais, destacam-se o aloxano e a estreptozotocina ${ }^{(23)}$

Muitos estudos realizados em animais puderam demonstrar os variados efeitos que a STZ pode ocasionar. Em estudo feito por Dall'AGO et al. ${ }^{(5)}$, observaram-se alterações na freqüência cardíaca e na pressão arterial, bem como na sensibilidade dos baro e quimioreceptores, quando comparados os animais diabéticos com os animais-controle.

O catabolismo dos aminoácidos e sua conseqüente utilização na formação de $\mathrm{CO}_{2}$ e $\mathrm{H}_{2} \mathrm{O}$ está aumentado no DM. Muitos aminoácidos são captados da corrente sangüínea e convertidos à glicose no fígado. Esse mecanismo parece ser uma das principais anormalidades do metabolismo intermediário presente no sistema hepático ${ }^{(8)}$.
No presente estudo, os animais diabéticos, no momento do sacrifício, apresentaram diminuição significativa no peso corporal, variando de $19 \%$ a $46 \%$ em relação aos animais do grupo-controle. A maior alteração ocorreu nos animais com 90 dias de DM. Houve diminuição de peso corporal, apesar de receberem alimentação e água ad libitum (Tabela 1).

Nos animais que permanecem por período prolongado de jejum, o glicogênio hepático é diminuído e o glicerol é convertido em glicose. Como esse mecanismo é muito limitado em algumas situações, os substratos para a formação da glicose sangüínea passam a ser as proteínas. Isso justificaria a diferença encontrada no peso corporal dos animais diabéticos neste trabalho. Estudo realizado por McNURLAN e GARLICK ${ }^{(18)}$ confirmou que a síntese das proteínas está diminuída em, aproximadamente, $50 \%$ no DM, além de conter baixos níveis na síntese protéica por unidade de RNA.

A hiperglicemia é fator de risco conhecido na patogênese do DM, podendo levar a diversas complicações. $\mathrm{O}$ exato mecanismo pelo qual o excesso de glicose determina alteração nos tecidos permanece desconhecido ${ }^{(26)}$. Diversos estudos demonstram que a hipótese mais provável é que o acúmulo de glicose leva ao estresse oxidativo e, assim, ocorreriam as complicações tardias do $\mathrm{DM}^{(22)}$.

Neste estudo, utilizou-se somente um grupo-controle para todas as variáveis estudadas, ou seja, compararam-se os animais diabéticos, nos diferentes tempos de indução com apenas um grupo-controle. Isso foi realizado porque os valores apresentados pelos animais do grupo-controle no momento do sacrifício, não apresentavam diferença significativa entre os diferentes grupos. Utilizou-se esse procedimento ao quantificar a glicemia, a lipoperoxidação e a atividade das enzimas antioxidantes no estômago e no fígado, bem como no fluxo sangüíneo da artéria mesentérica superior.

Notou-se aumento progressivo da glicemia nos diferentes tempos, sendo que, aos 90 dias, houve aumento de $280 \%$ em relação ao valor inicial apresentado pelo grupo-controle (Gráfico 1).

Muitos estudos mostram que as reações ocorridas com os radicais livres, como a peroxidação lipídica, estão aumentadas em diversas doenças. A alteração gastrointestinal causada pela administração de aloxano, outra droga utilizada para produzir o DM experimental, também provoca aumento na produção de radicais livres ${ }^{(4)}$.

Em recente trabalho publicado por De ANGELIS et al. ${ }^{(6)}$, foi avaliado o estresse oxidativo no músculo grande dorsal de ratos diabéticos induzidos por estreptozotocina com 5 dias de doença. Os resultados demonstraram que houve aumento na lipoperoxidação do músculo estudado, semelhantes aos obtidos na presente série. Nesse mesmo estudo, quando avaliada a atividade das enzimas antioxidantes CAT, SOD e GTx, houve aumento significativo nas atividades das enzimas CAT e GTx, e diminuição não significativa na atividade da enzima $\mathrm{SOD}^{(6)}$.

Quando analisada a atividade das enzimas antioxidantes CAT, SOD e GTx no estômago dos animais diabéticos, constatou-se diminuição em todas as enzimas nos diversos tempos e grupos estudados, e ocorreu diminuição significativa somente nas enzimas CAT e GTx, nos animais diabéticos com 7 e 90 dias (Gráficos 2, 3). Esses resultados diferem dos encontrados por De ANGELIS et al. ${ }^{(6)}$, para os quais a atividade da enzima CAT aumentou no grupo diabético. Supõe-se que tenha ocorrido mecanismo compensatório, provavelmente produzido pelo estresse oxidativo, pois o aumento da lipoperoxidação no músculo grande dorsal dos animais diabéticos determinou, também, aumento na atividade das enzimas CAT e GTx.

Constatou-se diminuição nas defesas antioxidantes, no estômago e no fígado, após 90 dias de DM. O provável responsável seria o aumento na produção do ânion superóxido, potente radical livre, cujo mecanismo 
proposto é que este se transforma em peróxido de hidrogênio e forma o radical hidroxil ${ }^{(20)}$, principal iniciador da lipoperoxidação. Isso causaria a remoção de um átomo de hidrogênio de um ácido graxo poliinsaturado, que está presente na membrana celular e determinaria o aumento na lipoperoxidação, que seria responsável pela maior formação do óxido nítrico, incrementando na formação do peroxinitrito. O mecanismo responsável pela diminuição na atividade da enzima catalase poderia ser ocasionado, também pelo aumento do óxido nítrico ${ }^{(13)}$.

Avaliou-se o malondealdeído tecidual e detectaram-se níveis mais elevados no DM do que os encontrados no grupo-controle. Isso estaria relacionado à diminuição da glutationa reduzida, pois a destruição da mucosa gástrica seria o fator causador de sua diminuição. O mecanismo proposto para explicar as constatações se baseia na diminuição da glutationa reduzida ser decorrente do estresse oxidativo aumentado e não ocasionada pela sua oxidação ${ }^{(11)}$.

Acredita-se que os resultados encontrados neste trabalho possam estar relacionados ao estresse oxidativo, pois houve diminuição na atividade das enzimas antioxidantes CAT e GTx nos animais diabéticos, além de aumento na lipoperoxidação no estômago, principalmente aos 90 dias.

O estresse oxidativo apresenta papel específico na patogênese da fibrose e nas doenças hepáticas. TSUKAMOTO et al. ${ }^{(27)}$ avaliaram a peroxidação lipídica no tecido hepático e encontraram correlação entre a lipoperoxidação e a fibrose tecidual produzida pelo fígado. Esse órgão, responsável pelo metabolismo e pela destoxificação de diversos agentes agressores, surge como importante tecido a ser avaliado no diabetes experimental.

Poucos estudos demonstram o efeito que o DM experimental causa no tecido hepático em relação às espécies ativas de oxigênio. GOLDIN et al. ${ }^{(11)}$ demonstraram aumento na lipoperoxidação em animais diabéticos induzidos por estreptozotocina decorrente do aumento no malondealdeído plasmático.

Houve aumento significativo na lipoperoxidação do tecido hepático no DM aos 90 dias, quando comparado ao grupo-controle (Tabela 3).

Quando se avalia a atividade da enzima antioxidante GTx no fígado de ratos diabéticos, observa-se diminuição significativa em sua atividade aos 60 e 90 dias (Figura 4), coincidindo com o aumento da lipoperoxidação aos 90 dias.
As defesas contra os radicais livres estão reduzidas no cérebro e no fígado de animais diabéticos, onde a glutationa está diretamente envolvida. A atividade das enzimas antioxidantes SOD e glutationa plasmática diminuiu, quando comparados pacientes com DM tipo I com aqueles que não possuíam a doença ${ }^{(11)}$. Isso, de certa forma, explicaria a diminuição na atividade das enzimas CAT e SOD no fígado dos animais diabéticos.

O fluxo medido na artéria mesentérica superior nos animais diabéticos, aos 90 dias, aumentou significativamente quando comparado ao grupocontrole, que permaneceu inalterado nos outros períodos estudados. Esse mecanismo parece estar relacionado com o aumento do estresse oxidativo e com a hiperglicemia dos animais diabéticos aos 90 dias.

O mecanismo da disfunção endotelial em pacientes com DM não está muito esclarecido, mas a geração de espécies ativas de oxigênio e de nitrogênio tem sido indicada como um dos fatores responsáveis ${ }^{(7)}$. MARRONI ${ }^{(17)}$ encontrou alteração no fluxo sangüíneo da mucosa gástrica em ratos anêmicos, o que leva a crer que o sistema gastrointestinal é passível de mudanças no fluxo sangüíneo frente a diferentes situações experimentais.

O principal fator responsável pelo aumento do fluxo sangüíneo pode ser a hiperglicemia encontrada nos animais diabéticos, principalmente aos 90 dias. Ela ativaria a síntese do óxido nítrico (potente vasodilatador) e causaria vasodilatação e hiperemia local ${ }^{(28)}$. Quando há aumento na formação do óxido nítrico, ele pode transformar-se em peroxinitrito e causar alterações vasculares, o que explicaria os resultados encontrados no presente estudo em relação ao fluxo sangüíneo.

A partir dos resultados obtidos neste trabalho, é possível supor que o estresse oxidativo esteja relacionado ao DM, através do aumento da lipoperoxidação e da diminuição na atividade das enzimas antioxidantes. Supõe-se que tempo de instalação do DM possa influenciar no metabolismo gastrointestinal.

\section{CONCLUSÃO}

O aumento do estresse oxidativo no estômago e no fígado dos animais diabéticos, bem como a alteração no fluxo sangüíneo da artéria mesentérica superior é influenciado pelo tempo de instalação da doença e pelo aumento da glicose sangüínea.

Dias AS, Llesuy S, Marroni CA, Marroni N. Gastrointestinal alterations in diabetes mellitus: oxidative stress and blood flow in the superior mesenteric artery - experimental study. Arq Gastroenterol 2004;41(2):108-13.

ABSTRACT - Background - Gastrointestinal symptoms are frequent in diabetes mellitus and may be related to the oxidative stress, which is defined by an imbalance between the pro-oxidant and antioxidant systems. Aims - To assess some of the gastrointestinal changes in the diabetes mellitus model, such as the oxidative stress in the stomach and liver of diabetic animals and the blood flow in the superior mesenteric artery at different times of study. Material and Methods - Male Wistar rats weighing 250-350 g were used and ascribed to four different groups as follows: group I - 7 days of diabetes, group II - 30 days of diabetes, group III - 60 days of diabetes, and group IV - 90 days of diabetes. Diabetes was obtained by administering streptozotocin (70 mg $/ \mathrm{kg}$ ) intraperitoneally. Results - A significant increase in liver and stomach lipoperoxidation of diabetic animals was found only at 90 days. A significant decrease in the activity of antioxidant enzymes catalase e glutathione transferase was found in stomach, whereas in liver only glutathione transferase was significantly decreased. The blood flow in the superior mesenteric artery of animals with 90 days of diabetes was increased as compared to controls. Conclusions - It is possible to suppose that the increase in the oxidative stress in stomach and liver as well as the change in the blood flow in the superior mesenteric artery are affected by the length of diabetes and the hyperglycemia found in the animals studied, which would determine gastrointestinal changes.

HEADINGS - Diabetes mellitus, experimental. Oxidative stress. Mesenteric arteries. Regional blood flow. Rats. 


\section{REFERÊNCIAS BIBLIOGRÁFICAS}

1. Bellomo G, Maggi E, Polli M, Agosta FG, Bollati P, Finardi G. Auto antibodies agains oxidatively modified low density lipoproteins in NIDDM. Diabetes 1991;44:60-6.

2. Boveris A, Chance B. The mitocondrial generation of hydrogen peroxide: genera properties and effect of hyperbaric oxygen. Biochem J 1973;134:707-16.

3. Buege JA, Aust SD. Microsomal lipid peroxidation. Meth Enzimol 1978;52:302-9.

4. Cross CE, Halliwell B, Borish ET, Pryor WA, Ames BN, Saul RL, McCord JM, Harman D. Oxygen radicals and human disease. Ann Intern Med 1987;107:526-45.

5. Dall'Ago P, Fernandes TG, Machado UF, Belló AA, Irigoyen MC. Baroreflex and chemoreflex dysfunction in streptozotocin-diabetic rats. Braz J Biol Res 1997;30:119-24

6. De Angelis KLD, Cestari IA, Barp J, Dall'Ago P, Fernandes TG, Homem-de-Bittencourt PI, Belló-Klein A, Belló AA, Llessuy S, Irigoyen MC. Oxidative stress in the latissimus dorsi muscle of diabetic rats. Braz J Biol Res 2000;33:1363-8.

7. Elhadd TA, Kennedy G, Hill A, McLaren M, Newton RW, Greene SA, Belch JJF Abnormal markers of endothelial cell activation and oxidative stress in children, adolescents and young adults with type 1 diabetes with no clinical vascular disease. Diabetes Metab Res Rev 1999;15:405-11.

8. Ganong WF. Review of medical physiology. $17^{\text {th }}$ ed. Los Altos, Calif.: Appleton \& Lange; 1995.

9. Gitlin N. The liver and systemic disease. New York: Churchill Livingstone; 1997.

10. Goldim JR, Raymundo MM. Pesquisa em saúde e direitos dos animais. $2^{\mathrm{a}}$ ed. Porto Alegre: HCPA; 1997.

11. Goldin E, Ardite E, Elizalde JI, Odriozola A, Panés J, Piqué JM, Fernandez-Checa JC. Gastric mucosal damage in experimental diabetes in rats: role of endogenous glutathione. Gastroenterology 1997;112:855-63

12. Gonzalez Flecha B, Llesuy S, Boveris A. Hydroperoxide-iniciated chemiluminescence: an assay for oxydative stress in biopsies of heart, liver and muscle. Free Radic Biol Med 1991;10:41-7

13. Halliwell B. Oxidative stress markers in human disease: application to diabetes and to evaluation of the effects of antioxidants. In: Packer L, Rösen P, Tritschler HJ, King GL, Azzi A, editors. Antioxidants in diabetes management. New York: Marcel Dekker 2000. p.33-52

14. Koch K. Gastric neuromuscular disfunction in diabetes mellitus. A review of symptoms, pathophysiology, and treatment. Dige Dis Sci 1999;44:1061-75.
15. Low PA, Nickander KK, Tritschler HJ. The roles of oxidative stress and antioxidant treatment in experimental diabetic neuropathy. Diabetes 1997;46:385-425.

16. Mannervick B, Guthenberg C. Glutathione transferase (human placenta). Meth Enzymol 1981;77:231-7.

17. Marroni N. Efeito da anemia crônica sobre a microcirculação e integridade da mucosa gástrica em ratos [tese]. Porto Alegre: Instituto de Ciências Básicas da Saúde - Departamento de Fisiologia; 1994.

18. McNurlan MA, Garlick PJ. Protein synthesis in liver and small intestine in protein deprivation and diabetes. Am J Physiol 1981;241:E238-E45.

19. Melo DAS. Comparação e análise da expressão do fator de ativação nuclear Kappa B (NFKB) e da eletrogastrografia em ratos normais e diabéticos [dissertação]. Porto Alegre: Instituto de Ciências Básicas da Saúde - Departamento de Fisiologia; 2001.

20. Meneguini R. A toxicidade do oxigênio. Ciência Hoje 1987;5:57-62.

21. Nourooz-Zadeh J, Tajaddini-Sarmadi J, McCarthy S, Betteridge DJ, Wolff SP. Elevated levels of authentic plasma hydroperoxides in NIDDM. Diabetes 1995;44:1054-8.

22. Packer L, Rösen P, Tritschler HJ, King GL, Azzi A. Antioxidants in diabetes management. New York: Marcel Dekker; 2000.

23. Pickup JC, Williams C. Textbook of diabetes. $2^{\text {nd }}$ ed. New York: Blackwell Science; 1997.

24. Soffer EE, Thongsawat S, Hoogwerf BJ, Shah A. Effect of acute hyperglicemia on jejunal compliance and peristaltic reflex in healthy humans. Dig Dis Sci 1999;44:50-5.

25. Takeuchi K, Ueshima K, Ohuchi T, Okabe S. Induction of gastric lesions and hypoglycemic response by food deprivation in streptozotocin-diabetic rats. Dig Dis Sci 1994;39:626-34.

26. Thompson KH, Godin DV. Micronutrients and antioxidants in the progression of diabetes. Nutr Res 1995;15:1377-410.

27. Tsukamoto H, Kim CM, Luo ZZ, Horn W, Su LC, Brittenham GM. Role of lipid peroxidation in vivo and in vitro models of liver fibrogenesis. Gastroenterology 1993; 104:1012A

28. Williamson JR, Chang K, Frangos M, Hasan KS, Ido Y, Kawamura T, Nyengaard JR, Van-den enden M, Kilo C, Tilton RG. Hyperglicaemic pseudohypoxia and diabetics complications. Diabetes 1993;42:801-8. 